\title{
Understand Cross-Cultural Analysis
}

\author{
Rana Sinha
}

\begin{abstract}
:
Cross-cultural analysis could be a very perplexing field to understand with many different viewpoints, aims and concepts. The origins of cross-cultural analysis in the 19th century world of colonialism was strongly grounded in the concept of cultural evolution, which claimed that all societies progress through an identical series of distinct evolutionary stages. The origin of the word culture comes from the Latin verb colere = "tend, guard, cultivate, till". This concept is a human construct rather than a product of nature. The use of the English word in the sense of "cultivation through education" is first recorded in 1510. The use of the word to mean "the intellectual side of civilization" is from 1805; that of "collective customs and achievements of a people" is from 1867. The term Culture shock was first used in 1940.
\end{abstract}

Keyword: Culture shock, culture studies, Cross-Cultural Analysis,

\section{A. INTRODUCTION}

\section{How do we define culture?}

There are literally hundreds of different definitions as writers have attempted to provide the all-encompassing definition.

Culture consists of language, ideas, beliefs, customs, taboos, codes, institutions, tools, techniques, works of art, rituals, ceremonies and symbols. It has played a crucial role in human evolution, allowing human beings to adapt the environment to their own purposes 
rather than depend solely on natural selection to achieve adaptive success. Every human society has its own particular culture, or sociocultural system. (Adapted from source: Encyclopaedia Britannica)

\section{Generally culture can be seen as consisting of three elements:}

- Values - Values are ideas that tell what in life is considered important.

- Norms - Norms consists of expectations of how people should behave in different situations.

- Artefacts - Things or material culture - reflects the culture's values and norms but are tangible and manufactured by man.

\section{Origins and evolution of Cross-cultural analysis}

The first cross-cultural analyzes done in the West, were by anthropologists like Edward Burnett Tylor and Lewis H Morgan in the 19th century. Anthropology and Social Anthropology have come a long way since the belief in a gradual climb from stages of lower savagery to civilization, epitomized by Victorian England. Nowadays the concept of "culture" is in part a reaction against such earlier Western concepts and anthropologists argue that culture is "human nature," and that all people have a capacity to classify experiences, encode classifications symbolically and communicate such abstractions to others.

Typically anthropologists and social scientists tend to study people and human behavior among exotic tribes and cultures living in far off places rather than do field work among white-collared literate adults in modern cities. Advances in communication and technology and socio-political changes started transforming the modern workplace yet there were no guidelines based on research to help people interact with other people from other cultures.

To address this gap arose the discipline of cross-cultural analysis or cross-cultural communication. The main theories of cross-cultural communication draw from the fields of anthropology, sociology, communication and psychology and are based on value differences among cultures. Edward T. Hall, Geert Hofstede, Fons Trompenaars, Shalom Schwartz and Clifford Geertz are some of the major contributors in this field. 


\section{B. DISCUSSION}

\section{How the social sciences study and analyze culture}

Cultural anthropologists focus on symbolic culture whereas archaeologists focus on material and tangible culture. Sociobiologists study instinctive behavior in trying to explain the similarities, rather than the differences between cultures. They believe that human behavior cannot be satisfactorily explained entirely by 'cultural', 'environmental' or 'ethnic' factors. Some sociobiologists try to understand the many aspects of culture in the light of the concept of the meme, first introduced by Richard Dawkins in his 1976 book The Selfish Gene.

Dawkins suggests the existence of units of culture - memes - roughly analogous to genes in evolutionary biology. Although this view has gained some popular currency, other anthropologists generally reject it.

\section{Different types of cross-cultural comparison methods}

Nowadays there are many types of Cross-cultural comparisons. One method is comparison of case studies. Controlled comparison among variants of a common derivation is another form of comparison. Typically anthropologists and other social scientists favor the third type called Cross-cultural studies, which uses field data from many societies to examine the scope of human behaviour and to test hypotheses about human behavior and culture.

Controlled comparison examines similar characteristics of a few societies while crosscultural studies uses a sufficiently large sample that statistical analysis can be made to show relationships or lack of relationships between certain traits in question. The anthropological method of holocultural analysis or worldwide cross-cultural analysis is designed to test or develop a proposition through the statistical analysis of data on a sample of ten or more non literate societies from three or more geographical regions of the world. 
In this approach, cultural traits are taken out of the context of the whole culture and are compared with cultural traits in widely diverse cultures to determine patterns of regularities and differences within the broad base of the study.

\section{Aims of cross-cultural analysis}

Cross-cultural communication or inter cultural communication looks at how people from different cultural backgrounds try to communicate. It also tries to produce some guidelines, which help people from different cultures to better communicate with each other.

Culture has an interpretative function for the members of a group, which share that particular culture. Although all members of a group or society might share their culture, expressions of culture-resultant behaviour are modified by the individuals' personality, upbringing and life-experience to a considerable degree. Cross-cultural analysis aims at harnessing this utilitarian function of culture as a tool for increasing human adaptation and improving communication.

Cross-cultural management is seen as a discipline of international management focusing on cultural encounters, which aims to discover tools to handle cultural differences seen as sources of conflict or miscommunication.

\section{How laypersons see culture}

It is a daunting challenge to convey the findings of research and field work and discuss cross-cultural issues in diverse contexts such as corporate culture, workplace culture and inter cultural competency as laypeople tend to use the word 'culture' to refer to something refined, artistic and exclusive to a certain group of "artists" who function in a separate sphere than ordinary people in the workplace. Some typical allusions to culture:

Culture is the section in the newspaper where they review theatre, dance performances or write book reviews etc.

Culture is what parents teach their kids and grandparents teach their grandchildren. 
"You don't have any culture," is what people say to you when you put your feet on the table at lunchtime or spit in front of guests.

"They just have a different culture," people say about those whose behaviour they don't understand but have to tolerate.

\section{Different models of cross-cultural analysis}

There are many models of cross-cultural analysis currently valid. The 'Iceberg' and the 'Onion' models are widely known. The popular 'Iceberg model' of culture developed by Selfridge and Sokolik, 1975 and W.L. French and C.H. Bell in 1979, identifies a visible area consisting of behaviour or clothing or symbols and artifacts of some form and a level of values or an invisible level.

Trying to define as complex a phenomenon as culture with just two layers proved quite a challenge and the 'Onion' model arose. Geert Hofstede (1991) proposed a set of four layers, each of which includes the lower level or is a result of the lower level. According to this view, 'culture' is like an onion that can be peeled, layer-by layer to reveal the content. Hofstede sees culture as "the collective programming of the mind which distinguishes the members of one group or category of people from another."

Cross-cultural analysis often plots 'dimensions' such as orientation to time, space, communication, competitiveness, power etc., as complimentary pairs of attributes and different cultures are positioned in a continuum between these.

\section{Hofstede dimensions to distinguish between cultures}

The five dimensions Hofstede uses to distinguish between national cultures are:

Power distance, which measures the extent to which members of society accept how power is distributed unequally in that society.

Individualism tells how people look after themselves and their immediate family only in contrast with Collectivism, where people belong to in-groups (families, clans or organizations) who look after them in exchange for loyalty. 
The dominant values of Masculinity, focussing on achievement and material success are contrasted with those of Femininity, which focus on caring for others and quality of life. Uncertainty avoidance measures the extent to which people feel threatened by uncertainty and ambiguity and try to avoid these situations.

Confucian dynamism. This Long-term versus Short-term Orientation measured the fostering of virtues related to the past, i.e., respect for tradition, importance of keeping face and thrift.

\section{Trompenaars dimensions to distinguish between cultures}

Trompenaars and Hampden-Turner (1997) adopt a similar onion-like model of culture. However, their model expands the core level of the very basic two-layered model, rather than the outer level. In their view, culture is made up of basic assumptions at the core level. These 'basic assumptions' are somewhat similar to 'values' in the Hofstede model.

Trompenaars and Charles Hampden-Turner use seven dimensions for their model of culture:

- Universalism vs Particularism (what is more important - rules or relationships?)

- Individualism vs Communitarianism (do we function in a group or as an individual?)

- Neutral vs Emotional (do we display our emotions or keep them in check?)

- Specific vs Diffuse (how far do we get involved?)

- Achievement vs Ascription (do we have to prove ourselves to gain status or is it given to us just because we are a part of a structure?)

- Attitude to Time

- Past- / present- / future-orientatedness

- Sequential time vs Synchronic time(do we do things one at a time or several things at once?)

- Internal vs External Orientation (do we aim to control our environment or cooperate with it?) 


\section{Criticism of current models}

One of the weaknesses of cross-cultural analysis has been the inability to transcend the tendency to equalize culture with the concept of the nation state. A nation state is a political unit consisting of an autonomous state inhabited predominantly by a people sharing a common culture, history, and language or languages. In real life, cultures do not have strict physical boundaries and borders like nation states. Its expression and even core beliefs can assume many permutations and combinations as we move across distances.

There is some criticism in the field that this approach is out of phase with global business today, with transnational companies facing the challenges of the management of global knowledge networks and multicultural project teams, interacting and collaborating across boundaries using new communication technologies.

Some writers like Nigel Holden (2001) suggest an alternative approach, which acknowledges the growing complexity of inter- and intra-organizational connections and identities, and offers theoretical concepts to think about organizations and multiple cultures in a globalizing business context.

\section{CONCLUSION}

In spite of all the shortcomings and criticisms faced by the Hofstede model, it is very much favoured by trainers and researchers. There are two reasons for this. Firstly, it is a wonderful and easy to use tool to quantify cultural differences so that they can be discussed. Discussing and debating differences is after all the main method of training and learning. Secondly, Hofstede's research at IBM was conducted in the workplace, so Hofstede tools brings cross-cultural analysis closer to the business side of the workplace, away from anthropology, which is a matter for universities. 


\section{References}

Furnham, A. (2004). Education and culture shock. Psychologist, 17(1), 16.

Habibi, H. (2018). PROTECTING NATIONAL IDENTITY BASED ON THE VALUE OF NATION LOCAL WISDOM. International Journal of Malay-Nusantara Studies, 1(2), 24-40.

Hogan, J. T. (1983). Culture-Shock and Reverse-Culture Shock: Implications for Juniors Abroad and Seniors at Home.

Langs, R. (2019). The evolution of the emotion-processing mind. Routledge.

Martinez, C. (2019). Culture Shock and College Success.

Paige, R. M., Cohen, A. D., \& Shively, R. L. (2004). Assessing the Impact of a StrategiesBased Curriculum on Language and Culture Learning Abroad. Frontiers: The interdisciplinary journal of study abroad, 10, 253-276.

Pantelidou, S., \& Craig, T. K. (2006). Culture shock and social support. Social psychiatry and psychiatric epidemiology, 41(10), 777-781.

Rajasekar, J., \& Renand, F. (2013). Culture shock in a global world: Factors affecting culture shock experienced by expatriates in Oman and Omani expatriates abroad. International Journal of Business and Management, 8(13), 144.

Orta, D., Murguia, E., \& Cruz, C. (2019). From struggle to success via Latina sororities: Culture shock, marginalization, embracing ethnicity, and educational persistence through academic capital. Journal of Hispanic Higher Education, 18(1), 41-58. 